\title{
AMENDMENTS
}

\section{Publisher Correction: A spatially orthogonal hierarchically porous acid-base catalyst for cascade and antagonistic reactions}

Mark A. Isaacs, Christopher M. A. Parlett (D), Neil Robinson (D), Lee J. Durndell, Jinesh C. Manayil(D), Simon K. Beaumont (D), Shan Jiang, Nicole S. Hondow (D), Alexander C. Lamb (D), Deshetti Jampaiah, Michael L. Johns, Karen Wilson and Adam F. Lee (i)

Correction to: Nature Catalysis https://doi.org/10.1038/s41929-020-00526-5, published online 26 October 2020.

In the version of this Article originally published, the affiliation for Simon K. Beaumont was incorrectly given as 'School of Physical Science and Technology, ShanghaiTech University, Shanghai, China'; it should have been 'Department of Chemistry, Durham University, Durham, UK'. In addition, the Supplementary Information showed an old affiliation for Shan Jiang. These errors have now been corrected.

Published online: 9 November 2020

https://doi.org/10.1038/s41929-020-00549-y

(C) The Author(s), under exclusive licence to Springer Nature Limited 2020 